\title{
Variceal bleeding is aggravated by portal venous invasion of hepatocellular carcinoma: a matched nested case-control study
}

Jihye Lim¹, Ha II Kim², Eunju Kim³, Jiyoon Kim, Jihyun An, Seheon Chang ${ }^{5}$, Seon-Ok Kim ${ }^{6}$, Han chu Lee ${ }^{1,7}$, Yung Sang Lee ${ }^{1,7}$ and Ju Hyun Shim ${ }^{1,7^{*}}$ (D)

\begin{abstract}
Background: We hypothesized that portal vein tumor thrombosis (PVTT) in hepatocellular carcinoma (HCC) increases portal pressure and causes esophageal varices and variceal bleedings. We examined the incidence of high-risk varices and variceal bleeding and determined the indications for variceal screening and prophylaxis.

Methods: This study included 1709 asymptomatic patients without any prior history of variceal hemorrhage or endoscopic prophylaxis who underwent upper endoscopy within 30 days before or after initial anti-HCC treatment. Of these patients, 206 had PVTT, and after 1:2 individual matching, 161 of them were matched with 309 patients without PVIT. High-risk varices were defined as large/medium varices or small varices with red-color signs and variceal bleeding. Bleeding rates from the varices were compared between matched pairs. Risk factors for variceal bleeding in the entire set of patients with PVIT were also explored.

Results: In the matched-pair analysis, the proportion of high-risk varices at screening (23.0\% vs. 13.3\%; $P=0.003)$ and the cumulative rate of variceal bleeding $(4.5 \%$ vs. $0.4 \%$ at 1 year; $P=0.009)$ were significantly greater in the PVIT group. Prolonged prothrombin time, lower platelet count, presence of extrahepatic metastasis, and Vp4 PVTT were independent risk factors related to high-risk varices in the total set of 206 patients with PVTT (Adjusted odds ratios [95\% Cls], 1.662 [1.151-2.401]; 0.985 [0.978-0.993]; 4.240 [1.783-10.084]; and 3.345 [1.457-7.680], respectively; Ps $<0.05)$. During a median follow-up of 43.2 months, 10 patients with PVTT experienced variceal bleeding episodes, 9 of whom (90\%) had high-risk varices. Presence of high-risk varices and sorafenib use for HCC treatment were significant predictors of variceal bleeding in the complete set of patients with PVIT (Adjusted hazard ratios [95\% Cls], 26.432 [3.230-216.289]; and 5.676 [1.273-25.300], respectively; $\mathrm{Ps}<0.05)$.

\footnotetext{
*Correspondence: s5854@amc.seoul.kr

'Department of Gastroenterology, Asan Medical Center, University of Ulsan College of Medicine, 88, Olympic-ro 43-gil, Songpa-gu, Seoul 05505, South Korea

${ }^{7}$ Asan Liver Center, Asan Medical Center, University of Ulsan College of Medicine, Seoul, Republic of Korea

Full list of author information is available at the end of the article
}

C C The Author(s). 2020 Open Access This article is licensed under a Creative Commons Attribution 4.0 International License, which permits use, sharing, adaptation, distribution and reproduction in any medium or format, as long as you give appropriate credit to the original author(s) and the source, provide a link to the Creative Commons licence, and indicate if changes were made. The images or other third party material in this article are included in the article's Creative Commons licence, unless indicated otherwise in a credit line to the material. If material is not included in the article's Creative Commons licence and your intended use is not permitted by statutory regulation or exceeds the permitted use, you will need to obtain permission directly from the copyright holder. To view a copy of this licence, visit http://creativecommons.org/licenses/by/4.0/. The Creative Commons Public Domain Dedication waiver (http://creativecommons.org/publicdomain/zero/1.0/) applies to the data made available in this article, unless otherwise stated in a credit line to the data. 
(Continued from previous page)

Conclusions: PVTT in HCC appears to increase the likelihood of high-risk varices and variceal bleeding. In HCC

patients with PVTT, endoscopic prevention could be considered, at least in high-risk variceal carriers taking sorafenib.

Keywords: Hepatocellular carcinoma, Portal vein thrombosis, Esophageal varices, Variceal bleeding, Risk factor

\section{Highlights}

Hepatocellular carcinoma with portal vein tumor thrombosis may increase the likelihood of developing high-risk varices and variceal bleeding.

The presence of high-risk varices and sorafenib use for hepatocellular carcinoma treatment were significant predictors of variceal bleeding.

\section{Background}

Variceal hemorrhage is one of the main causes of noncancer-related deaths in cirrhotic patients with hepatocellular carcinoma (HCC) [1-3]. Portal hypertensiondriven excessive wall tension is a substantial contributor to esophago-gastric variceal rupture $[4,5]$.

Portal vein tumor thrombosis (PVTT) has a significant effect on the prognosis of HCC patients, resulting in a short survival time comparable or often inferior to metastatic patients. Accordingly, these two HCC categories are both classified as advanced stage (stage $\mathrm{C}$ ) based on the Barcelona Clinic Liver Cancer (BCLC) system [6, 7]. Despite a lack of data on direct measurement of portal pressure in patients with HCC invading the portal vasculature, it is plausible that PVTT would secondarily enhance resistance and pressure in portal veins. Moreover, PVTT is robustly associated with variceal bleeding in HCC patients $[8,9]$. as it is in cirrhotic patients with benign portal vein thrombosis [10]. With the exception of individuals with mild liver stiffness and normal platelet count who have a very low probability of high-risk varices, routine screening endoscopy for examining esophago-gastric varices is formally recommended for almost all cirrhotic patients. Treatment with non-selective beta-blockers (NSBBs), or endoscopic variceal ligation (EVL), are recommended for non-bleeders with varices, depending on the severity of the varices $[5,11,12]$. However, there is no consensus about variceal evaluation and prevention specifically targeting HCC patients, who generally have a greater risk of developing varices and associated hemorrhagic events, and there are no current guidelines [13].

In view of the relevant practical and strategic needs, we investigated the incidence of subclinical varices on endoscopy, especially in the esophagus, in the initial work-ups of a set of cases with HCC and PVTT. We also compared bleeding rates from the varices or overall upper gastrointestinal tract during the HCC treatment or follow-up periods in a matched control set without PVTT. Potential risk factors for variceal bleeding in patients with HCC accompanied by PVTT were also explored.

\section{Methods \\ Study population}

This retrospective study included a total of 2750 patients originally diagnosed as having HCC without any cancerrelated symptoms at the Asan Medical Center, South Korea, between January 2007 and December 2015. The diagnosis of HCC was based on typical contrast-enhanced imaging criteria and/or pathological proof according to global practice guidelines [14-16]. Among these silent HCC patients, we excluded the following: 1) 1019 patients who did not undergo upper endoscopy for variceal screening within 30 days before or after initial anti-HCC treatment; 2) five who had a prior history of variceal hemorrhage; and 3) 17 who received prophylactic endoscopic therapy during the study period. The 1709 patients who were finally enrolled comprising 206 patients with PVTT and 1503 without PVTT (Fig. 1).

\section{Definitions of major parameters}

High-risk varices were defined as large/medium varices $(>5 \mathrm{~mm})$ or small varices $(\leq 5 \mathrm{~mm})$ with red-color signs, such as cherry-red spots, hematocystic spots, and red wale markings in the esophagus, which are known to be associated with a high likelihood of variceal hemorrhage $[5,17]$. In addition, degree of PVTT was classified based on location and extension by contrast-enhanced computed tomography or magnetic resonance imaging as established by the classification system of the Liver Cancer Study Group of Japan [6]: 1) Type Vp1 was defined as tumor thrombus formation by microscopy; 2) type $\mathrm{Vp} 2$ was defined as tumor thrombus involving the segmental branch of the portal vein or above; 3) type Vp3 was defined as tumor thrombus involving large branches of the portal vein; and 4) type $\mathrm{Vp} 4$ was defined as tumor thrombus involving the main trunk of the portal vein.

\section{Definitions of study endpoints}

Variceal bleeding was defined as a hemorrhagic event from the esophageal tract, with or without gastric varices identified by endoscopy, or with presence of large 


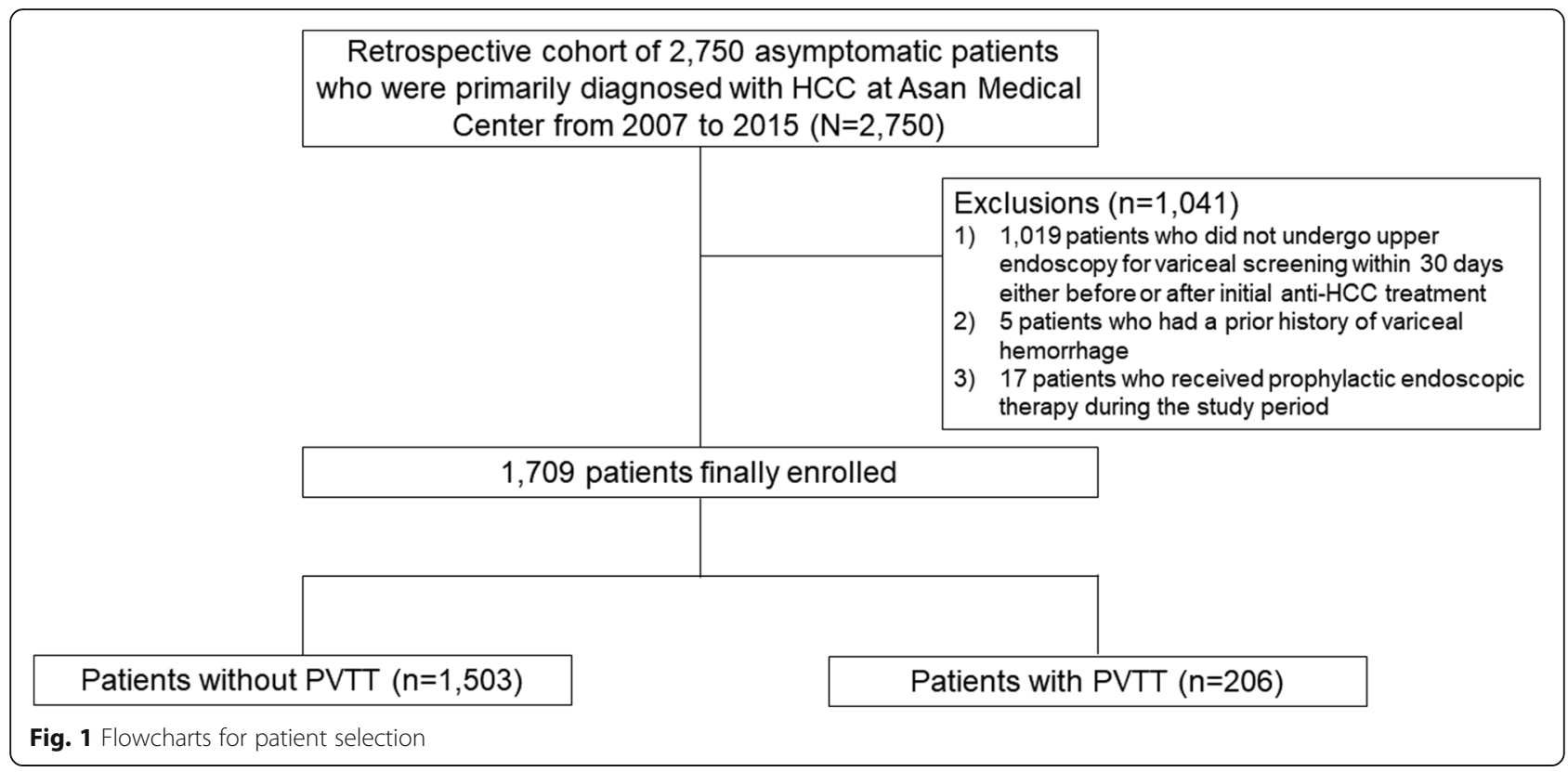

esophageal varices with blood in the stomach and no other visible bleeding foci. Overall bleeding was defined as any hemorrhagic episode arising from the upper gastrointestinal tract, including esophagus, stomach, and duodenum. Overall survival was calculated from the date of initiation of HCC treatment to death from any cause, or the date of last follow-up.

\section{Clinicopathological variables}

The following parameters were examined as clinical and pathological variables at initial HCC diagnosis that predict the presence of high-risk varices or bleeders: 1) patient-related factors including age, gender, hypertension, etiology of underling liver disease, Child-Pugh class, laboratory test data, ascites, and model for end-stage liver disease (MELD) score; 2) tumor-related factors including number of tumors, maximal size of tumors, serum alphafetoprotein (AFP) level, presence of extrahepatic metastasis, and extent of PVTT; and 3) treatmentrelated factors including NSBBs (specifically propranolol and carvedilol) and anti-HCC therapeutic methods (transarterial chemoembolization [TACE], radiotherapy, and sorafenib). All relevant information was obtained through our hospital's integrated healthcare system, consisting of a Picture Archiving Communication System and an Electronic Medical Record system (i.e., the Asan Medical Information System: AMIS). This complied with our Hospital Evaluation Program and Health Insurance Portability and Accountability Act (HIPAA) Standard Operating Procedures [18].

\section{Statistical analysis}

Statistical analysis was performed with SAS (version 9.4, SAS Institute, Inc., Cary, NC, USA) and $\mathrm{R}$ (version 3.6.0, https://www.r-project.org) software. The chi-square test or Fisher's exact test was used for categorical variables, and the t-test or MannWhitney test for continuous variables. Individual matching $(1,2)$ by Greedy algorithm for age $( \pm 5$ years), gender, hypertension, hepatitis B virus (HBV) infection, prothrombin time (PT), platelet, aspartate aminotransferase (AST), alanine aminotransferase (ALT), creatinine, ascites, and Child-Pugh class was performed to balance selection differences and reduce selection bias. Tumor burden and therapeutic method for $\mathrm{HCC}$, which depended directly on the presence or absence of PVTT were excluded from the matching variables. Using potential covariates that could affect clinical characteristics, we generated pairs of patients with and without PVTT. To compare the prevalence of varices in the matched set, logistic regression was performed with Generalized Estimating Equations (GEE), and the risks of variceal hemorrhage were compared with a Cox regression model, with robust standard errors, that accounted for the clustering of matched pairs. Subgroup analyses were performed for all HCC patients with PVTT to examine factors related to the formation of high-risk varices and variceal bleeding. Univariate and multivariable logistic regression analyses were performed to identify independent risk factors for high-risk varices. When evaluating the characteristics associated with variceal hemorrhage, a Cox proportional hazards model was used to 
establish the hazard ratio (HR) with a confidence interval (CI) of 95\%. The Cox model for overall survival included variceal hemorrhage as the timedependent covariate. Multivariable analyses were performed by backward elimination using variables with $P$-values of $<0.20$ in the univariate analysis. $P$-values $<0.05$ were considered statistically significant.

\section{Results}

Pre-endoscopic characteristics of the pooled and matched cohorts

The main demographic and clinical data of the pooled cohort are shown in Table 1. The mean age of the 1709 enrolled patients was $57.0 \pm 9.3$ years, and 1392 (81.5\%) were men. Liver cirrhosis was observed in all the

Table 1 Host and tumor characteristics of the pooled cohort

\begin{tabular}{|c|c|c|c|c|c|}
\hline \multirow[t]{2}{*}{ Variable } & \multicolumn{5}{|l|}{ Pooled cohort } \\
\hline & $\begin{array}{l}\text { All } \\
(n=1709)\end{array}$ & $\begin{array}{l}\text { Without PVTT } \\
(n=1503)\end{array}$ & $\begin{array}{l}\text { With PVTT } \\
(n=206)\end{array}$ & $\begin{array}{l}\text { Standardized } \\
\text { difference }\end{array}$ & $\begin{array}{l}P \text { - } \\
\text { value }\end{array}$ \\
\hline Age (years) & $57.0 \pm 9.3$ & $57.2 \pm 9.2$ & $55.5 \pm 9.5$ & 0.182 & 0.013 \\
\hline Male & $1392(81.5)$ & 1211 (80.6) & $181(87.9)$ & 0.201 & 0.012 \\
\hline Hypertension & $451(26.4)$ & $407(27.1)$ & $44(21.4)$ & 0.134 & 0.081 \\
\hline Etiology of liver disease & & & & 0.189 & 0.072 \\
\hline HBV infection & $1437(84.1)$ & $1254(83.4)$ & $183(88.8)$ & & \\
\hline HCV infection & $131(7.7)$ & $123(8.2)$ & $8(3.9)$ & & \\
\hline Others & $141(8.2)$ & $126(8.4)$ & $15(7.3)$ & & \\
\hline \multicolumn{6}{|l|}{ Child-Pugh class } \\
\hline A & 1564 (91.5) & $1380(91.8)$ & $184(89.3)$ & 0.085 & 0.228 \\
\hline B & $145(8.5)$ & $123(8.2)$ & $22(10.7)$ & & \\
\hline PT (INR) & $1.10 \pm 0.12$ & $1.09 \pm 0.12$ & $1.10 \pm 0.10$ & 0.033 & 0.115 \\
\hline Albumin $(\mathrm{g} / \mathrm{dl})$ & $3.8 \pm 0.5$ & $3.8 \pm 0.5$ & $3.7 \pm 0.5$ & 0.192 & 0.010 \\
\hline Bilirubin (mg/dl) & $1.0 \pm 0.9$ & $1.0 \pm 0.8$ & $1.1 \pm 1.6$ & & 0.036 \\
\hline Creatinine (mg/dl) & $0.9 \pm 0.6$ & $0.9 \pm 0.5$ & $0.9 \pm 1.0$ & 0.072 & 0.678 \\
\hline Platelet $\left(\times 10^{3} / \mathrm{uL}\right)$ & $133.1 \pm 57.2$ & $132.3 \pm 56.2$ & $139.4 \pm 63.6$ & 0.120 & 0.265 \\
\hline AST (IU/L) & $51.4 \pm 39.6$ & $50.6 \pm 38.3$ & $57.0 \pm 47.9$ & 0.147 & 0.204 \\
\hline ALT (IU/L) & $42.5 \pm 34.6$ & $42.3 \pm 33.7$ & $43.7 \pm 40.2$ & 0.037 & 0.755 \\
\hline Ascites & $49(2.9)$ & $31(2.1)$ & $18(8.7)$ & 0.299 & $<0.001$ \\
\hline MELD score & $8.2 \pm 2.3$ & $8.2 \pm 2.3$ & $8.4 \pm 2.5$ & 0.086 & 0.251 \\
\hline Liver cirrhosis & $1.709(100)$ & $1.503(100)$ & $206(100)$ & 0.000 & 0.999 \\
\hline Number of tumors & & & & 0.221 & 0.002 \\
\hline Single & $1115(65.3)$ & $1000(66.5)$ & $115(55.8)$ & & \\
\hline Multiple & $594(34.7)$ & $503(33.5)$ & $91(44.2)$ & & \\
\hline Infiltrative-type tumor & $99(5.8)$ & $23(1.5)$ & $76(36.9)$ & 1.004 & $<0.001$ \\
\hline Tumor size $(\mathrm{cm})$ & $3.9 \pm 2.8$ & $3.5 \pm 2.4$ & $7.2 \pm 3.5$ & 1.218 & $<0.001$ \\
\hline Serum AFP (ng/mL) & $2630.6 \pm 17,308.0$ & $1185.2 \pm 7501.9$ & $13,176.8 \pm 44,232.0$ & 0.378 & $<0.001$ \\
\hline Extrahepatic metastasis & $85(5.0)$ & $42(2.8)$ & $43(20.9)$ & 0.583 & $<0.001$ \\
\hline \multicolumn{6}{|c|}{ Primary anti-HCC treatment } \\
\hline TACE & $717(42.0)$ & $577(38.4)$ & $140(68.0)$ & 0.620 & $<0.001$ \\
\hline Radiotherapy* & $86(5.0)$ & $32(2.1)$ & $54(26.2)$ & 0.736 & $<0.001$ \\
\hline Sorafenib ${ }^{*}$ & $41(2.4)$ & $29(1.9)$ & $12(5.8)$ & 0.203 & 0.002 \\
\hline
\end{tabular}

Values are expressed as mean \pm standard deviation, or frequency (percentage)

PVTT portal vein tumor thrombosis, HBV hepatitis B infection, HCV hepatitis C virus, PT prothrombin time, INR international normalized ratio, AST aspartate aminotransferase, $A L T$ alanine aminotransferase, MELD model for end-stage liver disease, AFP alpha-fetoprotein, $H C C$ hepatocellular carcinoma, and TACE transarterial chemoembolization

*Of the 86 patients receiving radiotherapy, 77 were primarily treated with a TACE-combined regimen: 50 in the PVTT group and 27 in the non-PVTT group ${ }^{\ddagger}$ Of the 29 patients receiving sorafenib in the non-PVTT group, 19 were primarily treated with a TACE-combined regimen; while 12 patients with PVIT group only treated with sorafenib regimen 
patients. Most patients had HBV infection (84.1\%) and Child-Pugh class A liver disease (91.5\%). The mean MELD score was $8.2 \pm 2.3$. There were 451 (26.4\%) hypertensive patients. The PVTT group was younger (means \pm standard deviation [SD], $55.5 \pm 9.5$ vs. $57.2 \pm$ 9.2, $P=0.013)$, and included more men $(87.9 \%$ vs. $80.6 \%$, $P=0.012)$ and infiltrative-type tumors $(1.5 \%$ vs. $36.9 \%$, $P<0.001)$. Worse laboratory findings for albumin, bilirubin, and AFP levels were observed in the PVTT group $(3.7 \pm 0.5$ vs. $3.8 \pm 0.5,1.1 \pm 1.6$ vs. $1.0 \pm 0.8$; and 13 , $176.8 \pm 44,232.0$ vs. $1185.2 \pm 7501.9$, respectively; all Ps < 0.05). TACE (42.0\%) was the most common first-line treatment in both the PVTT and non-PVTT groups. Of the 86 patients receiving radiotherapy, 77 (50 in the PVTT group and 27 in the non-PVTT group) were primarily treated with a TACE-combined regimen. All of the 12 patients in the PVTT group were initially treated with sorafenib monotherapy, while 19 of the 29 patients in the non-PVTT group received sorafenib therapy combined with concurrent TACE.

After matching multiple covariates (i.e., age, sex, AST, ALT, PT, platelet, creatinine, hypertension, presence of ascites, HBV infection, and Child-Pugh class) in the pooled cohort, 161 patients with PVTT were matched with 309 controls without PVTT (Supplementary Table 1). Thirteen cases were matched to only one control in order to minimize case exclusion. There were thus 148 PVTT patients with 2 controls, and 13 with only one control. Among the matched pairs, it was evident that the PVTT group had more aggressive tumor characteristics in terms of tumor size $(7.1 \pm 3.6$ vs. $3.6 \pm 2.4)$, serum AFP level $(12,514.5 \pm 36,419.6$ vs. $1025.6 \pm$ 4349.6), multiple HCCs (44.7\% vs. $33.7 \%)$, and extrahepatic metastasis $(18.0 \%$ vs. $3.6 \%$; all $\mathrm{Ps}<0.05)$ (Supplementary Table 2).

\section{Endoscopic findings and preemptive medication in the matched cohort}

In the matched-pair analysis, higher percentages of overall esophageal varices (37.9\% vs. $26.5 \%$; odds ratio [OR] 1.689, [95\% CI, 1.116-2.446], $P=0.006$ ) and high-risk varices on initial endoscopic images $(23.0 \%$ vs. $13.3 \%$; OR, 1.950 [95\% CI, 1.262-3.104], $P=0.003$ ) were found in the PVTT group than in the non-PVTT group; there were no differences regarding gastric varices or portal hypertensive gastropathy (Table 2). The proportion of patients receiving prophylactic treatment with NSBBs did not differ between the two groups $(13.4 \%$ vs. $16.8 \%$; $P=0.423)$.

\section{Bleeding episodes and mortality in the matched cohort}

During a median follow-up of 43.2 months (range, 15.071.7 months), $13(8.1 \%)$ and $10(6.2 \%)$ of the PVTT group versus 17 (5.5\%) and $15(4.9 \%)$ of the non-PVTT group had overall and variceal bleeding episodes during the observation period, respectively, in the matched cohort $(P=0.279$ and $P=0.534$, respectively by Chisquare test). A significantly higher cumulative incidence of variceal bleeding was observed in the PVTT group, compared with the counterpart $(4.5 \%$ vs. $0.4 \%$ at 1 year; $7.9 \%$ vs. $2.7 \%$ at 3 year; and $7.9 \%$ vs. $5.7 \%$ at 5 years; HR 2.642, 95\% CI [1.270-5.497], $P=0.009$; Fig. 2a): no bleeding episode was originated from gastric varices alone. An additional multivariate Cox regression analysis also demonstrated that presence of PVTT was an independent risk factor for variceal bleeding in the pooled cohort (HR, 2.525 [95\% CI, 1.316-4.843], $P=0.005$; Supplementary Table 3). A similar pattern emerged in terms of overall hemorrhagic outcome $(6.6 \%$ vs. $0.7 \%$ at 1 year; $10.0 \%$ vs. $3.0 \%$ at 3 year; and $10.0 \%$ vs. $6.0 \%$ at 5 year; HR, 2.838 [95\% CI, 1.447-5.569], $P=0.002$; Fig. 2b); five cases with bleeding from gastric or duodenal ulcers $(n=3)$, or angiodysplasia $(n=2)$ were included in the overall bleeding events. As reported in previous studies, [14, 15, 19] median overall survival was significantly shorter in the PVTT group than in the non-PVTT group (1-year survival rates of $65.2 \%$ vs. $94.9 \%$; and 3 -year survival rates of $25.5 \%$ vs. $83.1 \%$, respectively; $P<0.001$; Supplementary Fig. 1 ).

\section{Risk factors associated with high-risk varices and variceal bleeding in the complete set of patients with PVTT}

Among the 206 patients with PVTT of whom 38 (18.4\%) took NSBBs and $58(28.2 \%)$ had high-risk varices by endoscopy, $\mathrm{Vp} 2, \mathrm{Vp} 3$, and $\mathrm{Vp} 4$ disease existed in 76 (36.9\%), 48 (23.3\%), and 82 (39.8\%), respectively. During the study period, acute variceal bleeding and all-cause

Table 2 Comparison of endoscopic findings in the matched cohort

\begin{tabular}{llllll}
\hline & Without PVTT (reference) & With PVTT & OR & 95\% Cl & P-value \\
\hline Esophageal varices & $82(26.5)$ & $61(37.9)$ & 1.689 & $1.116-2.446$ & 0.006 \\
High-risk varices & $41(13.3)$ & $37(23.0)$ & 1.950 & $1.262-3.104$ & 0.003 \\
Gastric varices & $34(11.0)$ & $23(14.3)$ & 1.348 & $0.794-2.290$ & 0.269 \\
Portal hypertensive gastropathy & $24(7.8)$ & $19(11.8)$ & 1.589 & $0.902-2.798$ & 0.109 \\
\hline
\end{tabular}

Values are expressed as frequency (percentage)

$P V T T$ portal vein tumor thrombosis, $O R$ odds ratio, and $\mathrm{Cl}$ confidence interval 

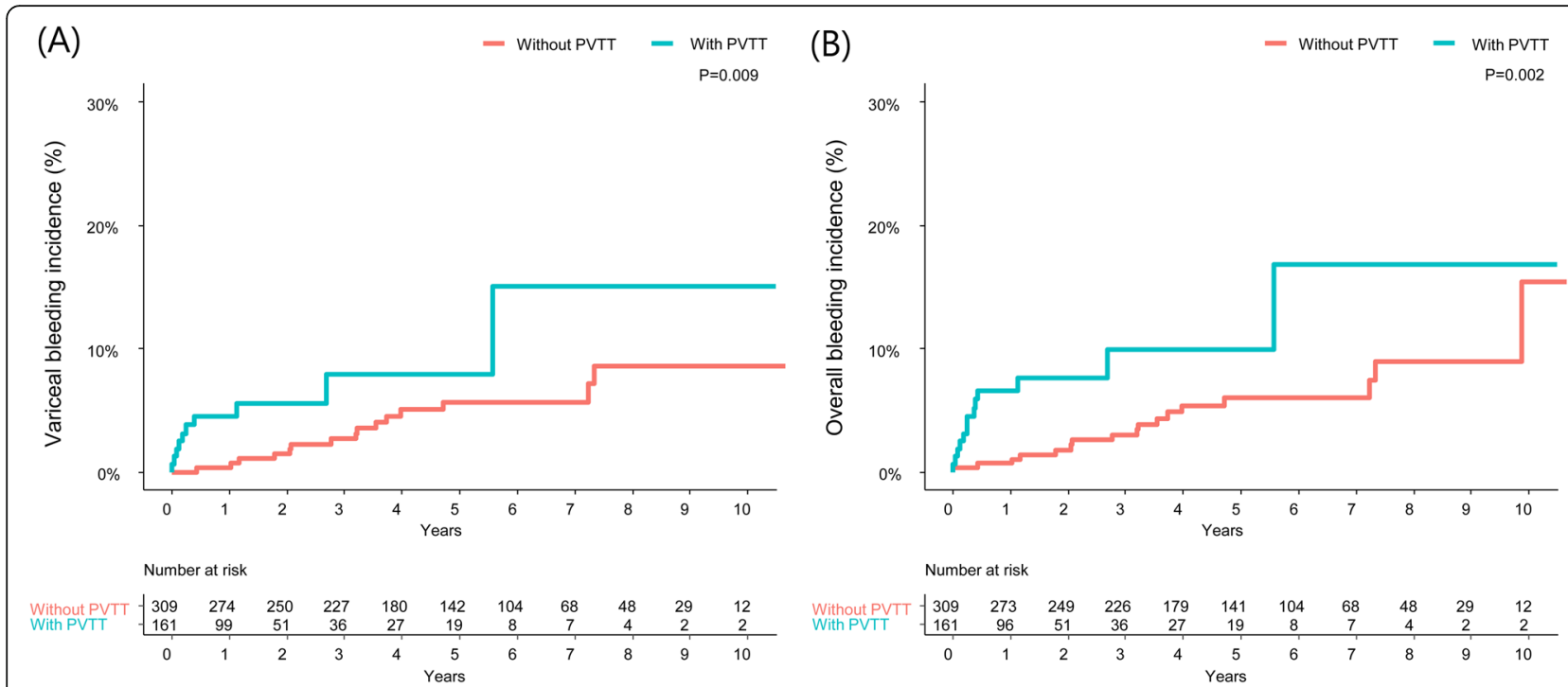

Fig. 2 Kaplan-Meier analysis for variceal bleeding and overall bleeding in the matched cohort, according to the presence of PVTT. Significantly higher cumulative incidence of $\mathbf{a}$ variceal bleeding, as well as $\mathbf{b}$ overall bleeding was observed in the PVTT group. PVTT, portal vein tumor thrombosis

mortality episodes occurred in 10 (4.9\%) and 166 (80.6\%), patients, respectively. Almost all bleeding (9/10, $90 \%$ ) originated from existing high-risk varices, and recurrent variceal bleeding was observed in 2 patients. Variceal bleeding per se did not correlate with long-term overall survival in the population with HCC and PVTT in the multivariate model (Supplementary Table 4). No bleeders died directly of their first episode during hospital stay, during which $8(80 \%)$ received emergent EVL in the early phase within $12 \mathrm{~h}$ of evidence of bleeding or admission to the emergency room. In a multivariate analysis of factors related to the presence of high-risk varices at screening in all patients with PVTT, prolonged PT (OR, 1.662 [95\% CI, 1.151-2.401], $P=0.007$ ), lower platelet count (OR, 0.985 [95\% CI, 0.978-0.993], $P<$ 0.001 ), presence of extrahepatic metastasis (OR, 4.240 [95\% CI, 1.783-10.084], $P=0.001$ ), and higher degree of Vp (Vp4; OR, 3.345 [95\% CI, 1.457-7.680], $P=0.004$ ) were significant (Table 3). A further multivariate model revealed that presence of high-risk varices (HR, 26.432 [95\% CI, 3.230-216.289], $P=0.002$ ) and sorafenib use (HR, 5.676 [95\% CI, 1.273-25.300], $P=0.023$ ) were independent predictors of variceal bleeding (Table 4 and Supplementary Fig. 2).

\section{Discussion}

In this matched study of asymptomatic HCC patients, we found that a quarter of patients with HCC invading the portal vein had high-risk varices in the esophagus in the initial endoscopic work-up, indicated by the presence of high-grade varices or red wale marks. Only about $6 \%$ experienced active variceal hemorrhages during the period of HCC treatment, and all but one of these bleeders had high-risk varices. The presence of PVTT was associated with a 2.6-fold higher risk of developing variceal bleeding over time, and this risk was independent of underlying liver function and coagulopathy, as well as the use of NSBBs.

The development of PVTT in patients with HCC is known to be mainly due to direct and contiguous vascular invasion by the tumor $[20,21]$. PVTT can cause an increase in portal hypertension, followed by rapid growth of venous collateral vessels, and may contribute to the development or aggravation of gastro-esophageal varices and potential hemorrhagic complications [22]. Clinical investigations have established a positive association between PVTT and high-risk varices and variceal hemorrhage in patients with $\mathrm{HCC}[8,9]$. This feature was also observed in cirrhotic patients with benign portal vein thrombosis [10]. In terms of primary prophylaxis for silent varices at risk of bleeding, it is currently advised that cirrhotic patients be initiated on NSBBs or considered for EVL [5, 11, 12, 17]. However, no guidelines have been set to deal specifically with the management of varices in patients with HCC, and this is the more unfortunate in that PVTT has been deemed a greater risk [13]. Sorafenib therapy, together with highrisk varices that are inherent risk factors [5], was a strong predictor of bleeding in the ruptured varices of our HCC patients with PVTT, with $30 \%$ of variceal bleeders taking the drug. In fact, beneficial roles of sorafenib have been reported in ameliorating portal pressure via it anti-angiogenic and anti-fibrotic effects in animal models [23-25]. However, a recent report revealed an increased risk of all-grade gastrointestinal hemorrhage due to the anti-VEGF effect associated with the use of 
Table 3 Analysis of factors affecting high-risk varices in the entire set of patients with PVTT $(n=206)$

\begin{tabular}{|c|c|c|c|c|c|c|c|c|}
\hline \multirow[t]{2}{*}{ Variable } & \multirow{2}{*}{$\begin{array}{l}\text { None or low-risk varices } \\
(n=148)\end{array}$} & \multirow{2}{*}{$\begin{array}{l}\text { High-risk varices } \\
(n=58)\end{array}$} & \multicolumn{3}{|c|}{ Univariate analysis } & \multicolumn{3}{|c|}{ Multivariate analysis } \\
\hline & & & OR & $95 \% \mathrm{Cl}$ & $P$-value & $\mathrm{OR}$ & $95 \% \mathrm{Cl}$ & $P$-value \\
\hline Age (years) & $55.3 \pm 9.8$ & $55.9 \pm 8.7$ & 1.007 & $0.976-1.040$ & 0.649 & & & \\
\hline Male & $129(87.2)$ & $52(89.7)$ & 1.276 & $0.483-3.376$ & 0.623 & & & \\
\hline Hypertension & $30(20.3)$ & $14(24.1)$ & 1.252 & $0.608-2.578$ & 0.543 & & & \\
\hline HBV infection & $131(88.5)$ & $52(89.7)$ & 1.125 & $0.420-3.010$ & 0.815 & & & \\
\hline Child-Pugh class & & & & & $<0.001$ & & & \\
\hline A (reference) & $139(93.9)$ & 45 (77.6) & 1.0 & - & - & & & \\
\hline B & $9(6.1)$ & $13(22.4)$ & 4.462 & $1.789-11.128$ & $<0.001$ & & & \\
\hline PT (INR) & $1.1 \pm 0.1$ & $1.2 \pm 0.1$ & 2.170 & $1.547-3.073$ & $<0.001$ & 1.662 & $1.151-2.401$ & 0.007 \\
\hline Creatinine (mg/dl) & $0.9 \pm 1.0$ & $1.0 \pm 0.8$ & 1.027 & $0.758-1.393$ & 0.863 & & & \\
\hline Platelet count $\left(\times 10^{3} / \mathrm{uL}\right)$ & $151.0 \pm 65.0$ & $109.9 \pm 48.9$ & 0.986 & $0.979-0.990$ & $<0.001$ & 0.985 & $0.978-0.993$ & $<0.001$ \\
\hline AST (IU/L) & $59.9 \pm 52.7$ & $49.6 \pm 32.0$ & 0.995 & $0.987-1.002$ & 0.175 & & & \\
\hline ALT (IU/L) & $45.2 \pm 45.6$ & $39.9 \pm 21.1$ & 0.996 & $0.987-1.005$ & 0.410 & & & \\
\hline Ascites & $8(5.4)$ & $10(17.2)$ & 3.646 & $1.360-9.771$ & 0.010 & & & \\
\hline \multicolumn{9}{|l|}{ Number of tumors } \\
\hline Single (reference) & $84(56.8)$ & $31(53.4)$ & 1.0 & - & - & & & \\
\hline Multiple & $64(43.2)$ & $27(46.6)$ & 1.143 & $0.621-2.104$ & 0.667 & & & \\
\hline Tumor size (cm) & $7.1 \pm 3.5$ & $7.4 \pm 3.7$ & 1.020 & $0.936-1.111$ & 0.651 & & & \\
\hline Serum AFP $(\mathrm{ng} / \mathrm{ml})$ & $12,401.0 \pm 33,830.0$ & $15,156.6 \pm 63,869.8$ & 1.001 & $0.995-1.008$ & 0.689 & & & \\
\hline Extrahepatic metastasis & $20(13.5)$ & $23(39.7)$ & 4.206 & $2.075-8.523$ & $<0.001$ & 4.240 & $1.783-10.084$ & 0.001 \\
\hline \multicolumn{9}{|l|}{ Degree of PVTT } \\
\hline Vp2 (reference) & $61(41.2)$ & $15(25.8)$ & 1.0 & - & - & 1.0 & - & - \\
\hline Vp3 & $41(27.7)$ & $7(12.1)$ & 0.694 & $0.260-1.851$ & 0.466 & 0.788 & $0.251-2.469$ & 0.682 \\
\hline Vp4 & $46(31.1)$ & $36(62.1)$ & 3.183 & $1.559-6.497$ & 0.001 & 3.345 & $1.457-7.680$ & 0.004 \\
\hline
\end{tabular}

Values are expressed as mean \pm standard deviation, or frequency (percentage)

PVTT portal vein tumor thrombosis, OR odds ratio, $\mathrm{Cl}$ confidence interval, HBV hepatitis B virus, PT prothrombin time, INR international normalized ratio, AST aspartate aminotransferase, $A L T$ alanine aminotransferase, and AFP alpha-fetoprotein

sorafenib in patients with $\mathrm{HCC}$, especially when the HCC was accompanied by underlying varices, thus affecting the architectural integrity of the endothelial cells of the microvasculature [26]. These findings suggest that although NSBBs may be more cost-effective and easier to administer to prevent first variceal bleeding in most cases with PVTT, [27] endoscopic eradication may be the best option at least in sorafenib-treated patients lacking the hemostatic benefit of portal depression by NSBBs $[28,29]$.

On the other hand, in our previous study of external beam radiotherapy mainly targeting PVTT induced by HCC we obtained a PVTT response rate of about $40 \%$ [30]. Given that resolution of the PVTT after radiotherapy could restore the interrupted portal venous supply of the liver, at least partially rescuing overall liver function, we hypothesized that PVTT shrinkage driven by radiotherapy lowers portal pressure, leading to decreased risk of variceal bleeding. However, radiotherapy did not affect the likelihood of variceal or overall bleeding episodes in our series.
Unexpectedly, we noted that existing high-risk varices and even variceal bleeding had no critical effect on the overall survival of our patients with HCC and PVTT. There have been contradictory findings regarding the effect of variceal bleeding on the long-term survival HCC patients [31-33]. There were no in-hospital deaths following the first active variceal bleeding episode in our subjects with HCC and PVTT, among whom $80 \%$ underwent emergent endoscopic therapy within $12 \mathrm{~h}$ of onset along with blood volume restitution and hemodynamic stabilization, although one bleeder did die of a serious recurrence of hemorrhage 6 weeks after the initial event. Indeed, early endoscopic confirmation followed by band ligation was able to lower the risk of re-bleeding as well as inhospital mortality in cirrhotic patients with acute variceal hemorrhage [34, 35].

The retrospective nature of this study has inherent limitations. Specifically, NSBBs were used to prevent 
Table 4 Factors predicting variceal bleeding episodes in the entire set of patients with PVTT $(n=206)$

\begin{tabular}{|c|c|c|c|c|c|c|c|c|}
\hline \multirow[t]{2}{*}{ Variable } & \multirow{2}{*}{$\begin{array}{l}\text { Without variceal bleeding } \\
(n=196)\end{array}$} & \multirow{2}{*}{$\begin{array}{l}\text { With variceal bleeding } \\
(n=10)\end{array}$} & \multicolumn{3}{|c|}{ Univariate analysis } & \multicolumn{3}{|c|}{ Multivariate analysis } \\
\hline & & & $\mathrm{HR}$ & $95 \% \mathrm{Cl}$ & $P$-value & $\mathrm{HR}$ & $95 \% \mathrm{Cl}$ & $P$-value \\
\hline Age (years) & $55.6 \pm 9.5$ & $52.9 \pm 7.9$ & 0.979 & $0.916-1.045$ & 0.523 & & & \\
\hline Male & $173(88.3)$ & $8(80.0)$ & 2.023 & $0.428-9.566$ & 0.374 & & & \\
\hline Hypertension & $42(21.4)$ & $2(20.0)$ & 0.997 & $0.210-4.723$ & 0.997 & & & \\
\hline HBV infection & $173(88.3)$ & $10(100.0)$ & & & & & & \\
\hline \multicolumn{9}{|l|}{ Child-Pugh class } \\
\hline A (reference) & $174(88.8)$ & $10(100.0)$ & & & & & & \\
\hline B & $22(11.2)$ & $0(0.0)$ & & & & & & \\
\hline NSBBS & $36(18.4)$ & $2(20.0)$ & 1.283 & $0.270-6.090$ & 0.754 & & & \\
\hline PT (INR) & $1.1 \pm 0.1$ & $1.2 \pm 0.1$ & 1.956 & $1.191-3.210$ & 0.008 & & & \\
\hline Creatinine (mg/dl) & $0.9 \pm 0.1$ & $0.9 \pm 0.2$ & 0.774 & $0.112-5.355$ & 0.795 & & & \\
\hline Platelet count $\left(\times 10^{3} / \mathrm{LL}\right)$ & $140.1 \pm 64.2$ & $127.2 \pm 51.4$ & 0.996 & $0.985-1.007$ & 0.528 & & & \\
\hline AST (IU/L) & $57.5 \pm 48.8$ & $48.3 \pm 26.4$ & 0.995 & $0.976-1.013$ & 0.576 & & & \\
\hline ALT (IU/L) & $43.9 \pm 40.8$ & $40.2 \pm 29.1$ & 0.997 & $0.975-1.018$ & 0.758 & & & \\
\hline Ascites & $18(9.2)$ & $0(0.0)$ & & & & & & \\
\hline \multicolumn{9}{|l|}{ Number of tumors } \\
\hline Single (reference) & $109(55.6)$ & $6(60.0)$ & 1.0 & - & - & & & \\
\hline Multiple & $87(44.4)$ & $4(40.0)$ & 1.151 & $0.316-4.194$ & 0.831 & & & \\
\hline Tumor size $(\mathrm{cm})$ & $7.1 \pm 3.5$ & $8.4 \pm 4.9$ & 1.237 & $0.258-5.929$ & 0.790 & & & \\
\hline Serum AFP (ng/ml) & $13,429.2 \pm 45,167.2$ & $8230.8 \pm 18,268.5$ & 1.154 & $0.976-1.364$ & 0.093 & & & \\
\hline Extrahepatic metastasis & $41(20.9)$ & $2(20.0)$ & 0.998 & $0.976-1.021$ & 0.875 & & & \\
\hline \multicolumn{9}{|l|}{ Degree of PVTT } \\
\hline Vp2 (reference) & $74(37.7)$ & $2(20.0)$ & 1.0 & - & - & & & \\
\hline Vp3 & $45(23.0)$ & $3(30.0)$ & 2.464 & $0.406-14.924$ & 0.327 & & & \\
\hline Vp4 & 77 (39.3) & $5(50.0)$ & 2.965 & $0.567-15.497$ & 0.198 & & & \\
\hline \multicolumn{9}{|l|}{ Primary anti-HCC treatment } \\
\hline TACE & $133(67.9)$ & $7(70.0)$ & 1.174 & $0.302-4.574$ & 0.817 & & & \\
\hline Radiotherapy & $52(26.5)$ & $2(20.0)$ & 0.753 & $0.160-3.554$ & 0.720 & & & \\
\hline Sorafenib & $9(4.6)$ & $3(30.0)$ & 11.615 & $2.809-48.030$ & 0.001 & 5.676 & $1.273-25.300$ & 0.023 \\
\hline High-risk varices & $49(25.0)$ & $9(90.0)$ & 31.323 & $3.928-249.782$ & 0.001 & 26.432 & $3.230-216.289$ & 0.002 \\
\hline
\end{tabular}

Values are expressed as the mean \pm standard deviation, or frequency (percentage)

PVTT portal vein tumor thrombosis, HR hazards ratio, Cl confidence interval, HBV hepatitis B virus, NSBB nonselective beta-blocker, PT prothrombin time, INR international normalized ratio, AST aspartate aminotransferase, ALT alanine aminotransferase, AFP alpha-fetoprotein, HCC hepatocellular carcinoma, and TACE transarterial chemoembolization

the first variceal hemorrhage in only one-third of the patients with high-risk varices. However, medical prophylaxis with NSBBs was not a significant preventive factor for variceal bleeding in our cohort. In fact, approximately $30 \%$ of candidates usually have contraindications to NSBBs therapy, or side effects that require cessation of the drug, as shown in prior trials [12].

\section{Conclusions}

In conclusion, HCC patients with PVTT mechanically enhancing portal hypertension are at increased risk of variceal bleeding, although only $15 \%$ of individuals with high-risk varices experienced actual episodes. Accordingly, patients with high-risk varices should undergo prophylaxis in essentially the same manner as the general cirrhotic population. In particular, sorafenib users, with the increased risk of bleeding, probably through microvascular disintegration, may prefer to be endoscopically prevented. Optimal prophylactic indications and methods for preventing potential variceal hemorrhage in HCC patients with PVTT should be clarified by prospective studies. 


\section{Supplementary Information}

The online version contains supplementary material available at https://doi. org/10.1186/s12885-020-07708-1

Additional file 1: Supplementary Table 1. Demographic and clinical characteristics of the matched cohort. Supplementary Table 2. Tumor characteristics of the matched cohort $(n=470)$. Supplementary

Table 3. Factors predicting variceal bleeding episodes in the pooled cohort $(n=1709)$. Supplementary Table 4. Analysis of factors affecting overall survival in the entire set of patients with PVTT $(n=206)$.

Supplementary Figure 1. Kaplan-Meier analysis for overall survival in matched cohort, according to the presence of PVTT. Supplementary Figure 2. Kaplan-Meier analysis for variceal bleeding incidence in the entire patients with PVTT according to the presence of high-risk varices and sorafenib use.

\section{Abbreviations}

AFP: Alpha-fetoprotein; ALT: Alanine aminotransferase; AST: Aspartate aminotransferase; BCLC: Barcelona Clinic Liver Cancer; Cl: Confidence interval; EVL: Endoscopic variceal ligation; HBV: Hepatitis B infection;

HCC: Hepatocellular carcinoma; HCV: Hepatitis C virus; HR: Hazard ratio; INR: International normalized ratio; MELD: Model for end-stage liver disease; NSBBs: Non-selective beta-blockers; PT: Prothrombin time; PVTT: Portal vein tumor thrombosis; TACE: Transarterial chemoembolization

\section{Acknowledgements}

Not applicable.

\section{Authors' contributions}

$J$ contributed to study design, interpretation of data, drafting of manuscript. HIK, EK, JK, JA, and SC contributed to study design, acquisition, interpretation of data. SOK contributed to analysis and interpretation of data. HCL and YSL contributed to critical revision of manuscript. JHS contributed to study concept, study design, and critical revision of manuscript for important intellectual content. All authors read and approved the final manuscript.

\section{Funding}

This study was supported by grants from the Basic Science Research Program through the National Research Foundation of Korea funded by the Ministry of Science and ICT (NRF-2017R1E1A1A01074298), and grant 2016076 from the Asan Institute for Life Sciences of Asan Medical Center. None of the funding sources had any role in study design, data collection, analysis or interpretation of findings, or drafting of the manuscript.

\section{Availability of data and materials}

The datasets generated during the current study are available from the corresponding author on reasonable request.

\section{Ethics approval and consent to participate}

This study protocol was approved by the Ethics Committee of Asan Medical Center (IRB No. 2019-0545), and this study was conducted in accordance with the Declaration of Helsinki. Because this study is based on the retrospective analysis of existing clinical data, the requirement of obtaining informed patient consent was waived by the Institutional Review Board.

\section{Consent for publication}

Not applicable.

\section{Competing interests}

The authors declare no underlying conflicts of interest.

\section{Author details}

${ }^{1}$ Department of Gastroenterology, Asan Medical Center, University of Ulsan College of Medicine, 88, Olympic-ro 43-gil, Songpa-gu, Seoul 05505, South Korea. ${ }^{2}$ Gastroenterology, Kyung Hee University Hospital, Seoul, Republic of Korea. ${ }^{3}$ Gastroenterology, Department of Internal Medicine, Haeundae Paik Hospital, College of Medicine, Inje University, Busan, Republic of Korea. ${ }^{4}$ Gastroenterology, Hanyang University College of Medicine, Guri, Gyeonggi-do, Republic of Korea. ${ }^{5}$ Internal Medicine, Myongji St. Mary's Hospital, Seoul, Republic of Korea. 'Biostatistics and Clinical Epidemiology,
Asan Medical Center, University of Ulsan College of Medicine, Seoul, Republic of Korea. 'Asan Liver Center, Asan Medical Center, University of Ulsan College of Medicine, Seoul, Republic of Korea.

Received: 18 June 2020 Accepted: 3 December 2020

Published online: 05 January 2021

\section{References}

1. Couto OF, Dvorchik I, Carr BI. Causes of death in patients with unresectable hepatocellular carcinoma. Dig Dis Sci 2007;52(11):32853289. Epub 2007/04/17

2. Hsieh WY, Chen PH, Lin IY, Su CW, Chao Y, Huo TI, et al. The impact of esophagogastric varices on the prognosis of patients with hepatocellular carcinoma. Sci Rep 2017;7:42577. Epub 2017/02/18.

3. D'Avola D, Inarrairaegui M, Pardo F, Rotellar F, Marti P, Bilbao Jl, et al. Prognosis of hepatocellular carcinoma in relation to treatment across BCLC stages. Ann Surg Oncol 2011;18(7):1964-1971. Epub 2011/01/27.

4. Jackson FW, Adrain AL, Black M, Miller LS. Calculation of esophageal variceal wall tension by direct sonographic and manometric measurements. Gastrointest Endosc 1999:50(2):247-251. Epub 1999/07/30.

5. European Association for the Study of the Liver. EASL clinical practice guidelines for the management of patients with decompensated cirrhosis. J Hepatol 2018;69(2):406-460. Epub 2018/04/15

6. Ye JZ, Ye HH, Xie S, Duan WL, Bai T, Chen J, et al. Indications and treatment of hepatocellular carcinoma with portal vein tumor thrombus based on two classifications. Int J Clin Exp Med. 2016:9(6):9021-32.

7. Sinn DH, Cho JY, Gwak GY, Paik YH, Choi MS, Lee JH, et al. Different survival of Barcelona clinic liver cancer stage $C$ hepatocellular carcinoma patients by the extent of portal vein invasion and the type of extrahepatic spread. PLoS One 2015;10(4):e0124434. Epub 2015/04/30.

8. Yeh JL, Peng YC, Tung CF, Chen GH, Chow WK, Chang CS, et al. Clinical predictors of large esophagogastric varices in patients with hepatocellular carcinoma. Dig Dis Sci 2002;47(4):723-729. Epub 2002/05/07.

9. Kadouchi K, Higuchi K, Shiba M, Okazaki H, Yamamori K, Sasaki E, et al. What are the risk factors for aggravation of esophageal varices in patients with hepatocellular carcinoma? J Gastroenterol Hepatol 2007;22(2):240-246. Epub 2007/02/14

10. Qi X, Su C, Ren W, Yang M, Jia J, Dai J, et al. Association between portal vein thrombosis and risk of bleeding in liver cirrhosis: a systematic review of the literature. Clin Res Hepatol Gastroenterol. 2015;39(6):683-91.

11. Augustin S, Pons M, Maurice JB, Bureau C, Stefanescu H, Ney M, et al. Expanding the Baveno $\mathrm{VI}$ criteria for the screening of varices in patients with compensated advanced chronic liver disease. Hepatology. 2017;66(6): 1980-1988. Epub 2017/07/12.

12. Garcia-Tsao G, Abraldes JG, Berzigotti A, Bosch J. Portal hypertensive bleeding in cirrhosis: risk stratification, diagnosis, and management: 2016 practice guidance by the American association for the study of liver diseases. Hepatology. 2017;65(1):310-335. Epub 2016/10/28

13. Giannini EG, Risso D, Testa R, Trevisani F, Di Nolfo MA, Del Poggio P, et al. Prevalence and prognostic significance of the presence of esophageal varices in patients with hepatocellular carcinoma. Clin Gastroenterol Hepatol 2006:4(11):1378-1384. Epub 2006/10/25

14. European Association for the Study of the Liver. EASL clinical practice guidelines: management of hepatocellular carcinoma. J Hepatol 2018;69(1): 182-236. Epub 2018/04/10

15. Marrero JA, Kulik LM, Sirlin CB, Zhu AX, Finn RS, Abecassis MM, et al. Diagnosis, staging, and management of hepatocellular carcinoma: 2018 practice guidance by the American Association for the Study of Liver Diseases. Hepatology. 2018;68(2):723-750. Epub 2018/04/07.

16. Omata M, Cheng AL, Kokudo N, Kudo M, Lee JM, Jia J, et al. Asia-Pacific clinical practice guidelines on the management of hepatocellular carcinoma: a 2017 update. Hepatol Int 2017;11(4):317-370. Epub 2017/ 06/18.

17. Sarin SK, Kumar A, Angus PW, Baijal SS, Chawla YK, Dhiman RK, et al. Primary prophylaxis of gastroesophageal variceal bleeding: consensus recommendations of the Asian Pacific Association for the Study of the liver. Hepatol Int 2008:2(4):429-439. Epub 2009/08/12

18. Ryu HJ, Kim WS, Lee JH, Min SW, Kim SJ, Lee YS, et al. Asan medical information system for healthcare quality improvement. Healthc Inform Res 2010;16(3):191-197. Epub 2011/08/06. 
19. Lerose R, Molinari R, Rocchi E, Manenti F, Villa E. Prognostic features and survival of hepatocellular carcinoma in Italy: impact of stage of disease. Eur J Cancer 2001;37(2):239-245. Epub 2001/02/13.

20. Intagliata NM, Caldwell SH, Tripodi A. Diagnosis, development, and treatment of portal vein thrombosis in patients with and without cirrhosis. Gastroenterology. 2019;156(6):1582-1599 e1. Epub 2019/02/17.

21. Valla DC, Condat B. Portal vein thrombosis in adults: pathophysiology, pathogenesis and management. J Hepatol 2000;32(5):865-871. Epub 2000/ 06/14.

22. Parikh S, Shah R, Kapoor P. Portal vein thrombosis. Am J Med 2010;123(2): 111-119. Epub 2010/01/28

23. Mejias M, Garcia-Pras E, Tiani C, Miquel R, Bosch J, Fernandez M. Beneficial effects of sorafenib on splanchnic, intrahepatic, and portocollateral circulations in portal hypertensive and cirrhotic rats. Hepatology. 2009;49(4): 1245-56.

24. Yang Y-Y, Liu R-S, Lee P-C, Yeh Y-C, Huang Y-T, Lee W-P, et al. Anti-VEGFR agents ameliorate hepatic venous dysregulation/microcirculatory dysfunction, splanchnic venous pooling and ascites of NASH-cirrhotic rat. Liver Int. 2014;34(4):521-34.

25. Hennenberg M, Trebicka J, Stark C, Kohistani AZ, Heller J, Sauerbruch T. Sorafenib targets dysregulated rho kinase expression and portal hypertension in rats with secondary biliary cirrhosis. Br J Pharmacol. 2009; 157(2):258-70.

26. Duffy A, Wilkerson J, Greten TF. Hemorrhagic events in hepatocellular carcinoma patients treated with antiangiogenic therapies. Hepatology. 2013; 57(3):1068-1077. Epub 2012/11/01.

27. Seo YS. Prevention and management of gastroesophageal varices. Clin Mol Hepatol. 2018;24(1):20.

28. Garcia-Pagan JC, De Gottardi A, Bosch J. Review article: the modern management of portal hypertension--primary and secondary prophylaxis of variceal bleeding in cirrhotic patients. Aliment Pharmacol Ther 2008;28(2): 178-186. Epub 2008/05/09.

29. Dai C, Zhou F, Shao JH, Wu LQ, Yu X, Yin XB. Bleeding risk in cancer patients treated with sorafenib: a meta-analysis of randomized controlled trials. J Cancer Res Ther 2018;14(12):948-956. Epub 2018/12/13.

30. Yoon SM, Lim YS, Won HJ, Kim JH, Kim KM, Lee HC, et al. Radiotherapy plus transarterial chemoembolization for hepatocellular carcinoma invading the portal vein: long-term patient outcomes. Int J Radiat Oncol Biol Phys 2012; 82(5):2004-2011. Epub 2011/05/31.

31. Lang BH, Poon RT, Fan ST, Wong J. Outcomes of patients with hepatocellular carcinoma presenting with variceal bleeding. Am J Gastroenterol 2004;99(11):2158-2165. Epub 2004/11/24.

32. Merkel C, Zoli M, Siringo $S$, van Buuren $H$, Magalotti $D$, Angeli $P$, et al. Prognostic indicators of risk for first variceal bleeding in cirrhosis: a multicenter study in 711 patients to validate and improve the north Italian endoscopic Club (NIEC) index. Am J Gastroenterol 2000;95(10):2915-2920. Epub 2000/10/29.

33. Kim JH, Sinn DH, Kim K, Kang W, Gwak GY, Paik YH, et al. Primary prophylaxis for variceal bleeding and the improved survival of patients with newly diagnosed hepatocellular carcinoma. Dig Dis Sci 2016;61(11):33543362. Epub 2016/10/19.

34. Chen PH, Chen WC, Hou MC, Liu TT, Chang CJ, Liao WC, et al. Delayed endoscopy increases re-bleeding and mortality in patients with hematemesis and active esophageal variceal bleeding: a cohort study. J Hepatol 2012;57(6):1207-1213. Epub 2012/08/14.

35. Hsu YC, Chung CS, Tseng CH, Lin TL, Liou JM, Wu MS, et al. Delayed endoscopy as a risk factor for in-hospital mortality in cirrhotic patients with acute variceal hemorrhage. J Gastroenterol Hepatol 2009;24(7):1294-1299. Epub 2009/08/18.

\section{Publisher's Note}

Springer Nature remains neutral with regard to jurisdictional claims in published maps and institutional affiliations.

Ready to submit your research? Choose BMC and benefit from:

- fast, convenient online submission

- thorough peer review by experienced researchers in your field

- rapid publication on acceptance

- support for research data, including large and complex data types

- gold Open Access which fosters wider collaboration and increased citations

- maximum visibility for your research: over $100 \mathrm{M}$ website views per year

At BMC, research is always in progress.

Learn more biomedcentral.com/submissions 